\title{
An Intelligent Monitoring System for a Crude Oil Distillation Column
}

\begin{abstract}
This paper describes an intelligent monitoring system for a crude oil distillation column. It proposes the use of multiple sensors to create a systematic way of monitoring, refining and detecting faults and anomalies. There can be sensor redundancy in a refinery and this research uses that redundancy for a crude distillation column to provide enough data and information to apply systemic methods and thinking and to create an intelligent monitoring system. The system uses real-time data from combinations of sensors used to observe crude refining to provide new information that would not be available from individual sensors. As an example, some sensor combinations are described for surveillance, to eliminate anomalies, and to improve monitoring with some intelligence.
\end{abstract}

Keywords - sensor; crude; distillation; column; intelligent; monitoring

\section{INTRODUCTION}

From an information technology perspective, the process of reservoir extraction and refining of crude in the oil and gas industry can be considered as a closed uniform environment. That environment contains a mixture of varying pressures and temperatures. If not monitored carefully then the varying pressures and temperatures could result in a catastrophic event.

There are many sensors in a refinery and it can be timeconsuming and labour intensive to keep track of all the sensors and the functionality of those sensors. Even with periodic maintenance, faults may not always be detected $[1,2]$

Understanding sensor functionality and recognizing data patterns from sensors is also time consuming. Refineries, might benefit from machine learning data analytics and multisensor pattern recognition techniques. Durrant emphasized the need for using data mining and machine learning techniques to obtain information and knowledge from data collected in the oil industry. The past couple of decades have seen an increased use of data mining techniques across all branches of science and engineering [5-8].

Detecting sensor data faults in a refinery is important:

- It is useful in making important decisions on whether or not to stop production before reaching a critical stage, especially if crucial information is missing.

- Predicting faults from recorded sensor data would be useful in determining the kind of maintenance needed.

- Recurring faults in historical data covering a long period would produce information about quality.
- Knowledge gained from sensor data could lead to improved design and engineering for a refinery.

\section{SENSORS}

Sensors are devices designed to receive prompts and respond with an electrical signal, and their outputs can be modified and be amplified by electronic devices.

Sensors are energy converters and some of the quantities that would be sensed include; motion, displacement, force, strain, pressure, flow, sound, moisture, light intensity, radiation, temperature, chemical presence velocity and acceleration. Sensor fusion is a process of combining data from multiple sources into one more sophisticated model to make a data set more accurate or to generate new higher level information. Sensor fusion can be classified according to the type of sensor configuration.

There are three types of sensor configuration [3]:

- Complementary (if sensors do not directly depend on each other, but can be combined),

- Competitive (when each sensor delivers independent measurements of the same property)

- Cooperative (when the sensor network uses the information provided by two independent sensors to derive information that is not be available from the single sensors) [3].

Fig. 1 shows the three types of sensor configuration.

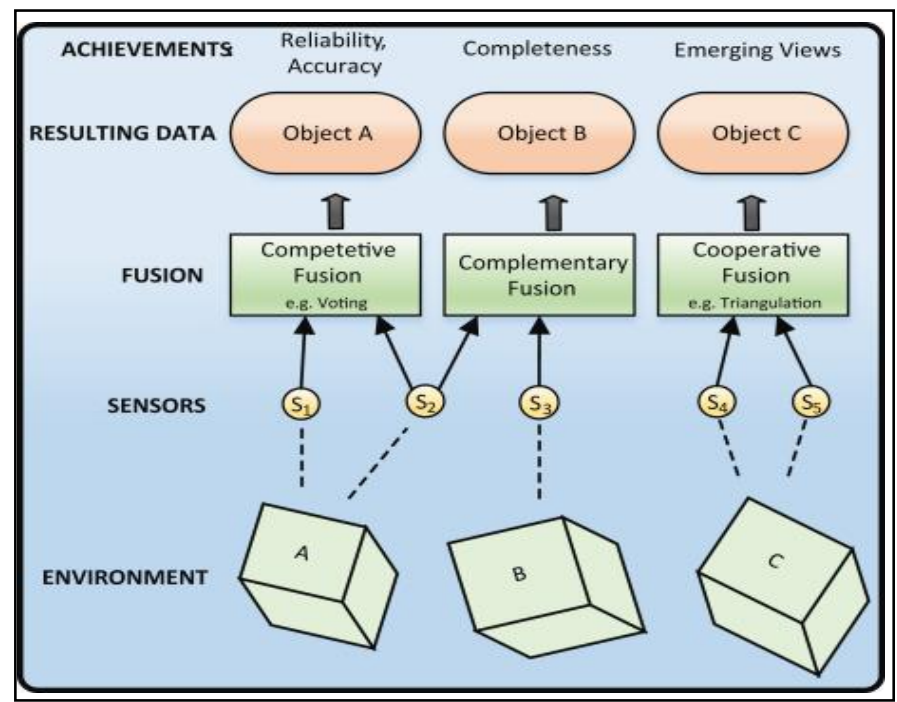

Figure 1. Competitive, complementary and cooperative fusion [3] 


\section{A. Sensors in Crude Distillation}

Distillation processes take place within closed apparatus, so the status and dynamics are not as evident as they might be within other processes, for example manufacturing. To control a distillation process, a priori knowledge of its properties and dynamics was required, together with information about processes that characterized the status of distillation. Fig. 2 shows the sensors being considered during this research.

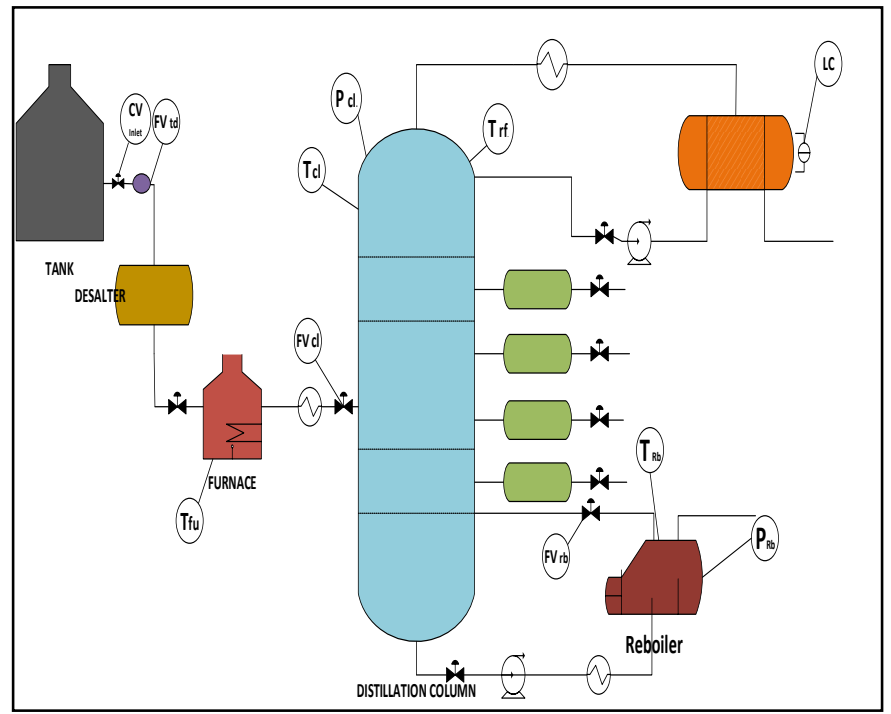

Figure 2. Sensors in a crude distillation column

Sensors identified in fig. 2 included: Crude inlet Valve (CV Inlet), Flow Transmitter (FV), Temperature at the furnace (Tfu), Temperature at column $(\mathrm{Tcl})$, Pressure at column $(\mathrm{Pcl})$, Level control (LC), Reflux Temperature (Trf), Temperature at the reboiler $(\mathrm{TRb})$, Pressure at the reboiler $(\mathrm{PRb})$.

\section{B. Sensor fusion}

Many types of sensors are used to gather information and there was a variety of sensors associated with distillation. Research is focusing on multi-sensor data fusion. Sensor fusion involved combining data from different sensors to create new information at a level above the process and environment. Fig. 3 shows how data fusion techniques combine data from multiple sensors and related information to achieve more specific inferences than could be achieved by using a single, independent sensor.

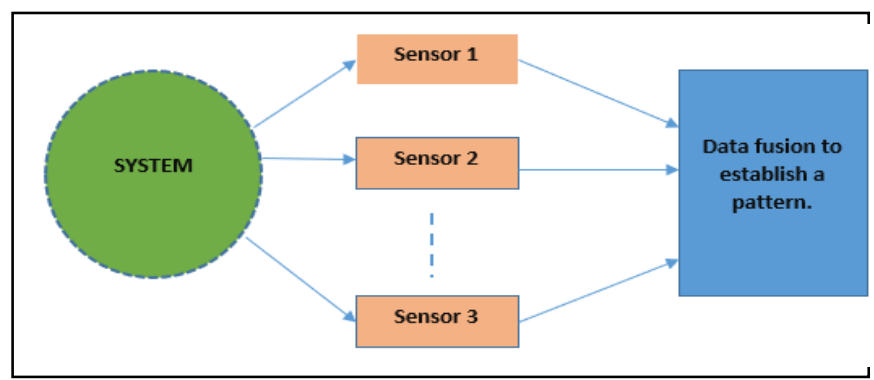

Figure 3. Systemic sensor fusion
Multi-sensor data fusion is not new. As humans and animals had evolved, they had developed the ability to use multiple senses. For example, assessing the quality of an edible substance might not be possible using vision only; a combination of sight, touch, smell, and taste can be far more effective. Similarly, when a single sense such as vision is limited (possibly by structures or vegetation) then a sense of hearing could help to provide warning of impending danger. Thus, multisensory data fusion is natural. Different sensors have the ability to provide data about different aspects and can have an ability to interact when put together [11].

Multi-sensor fusion has been defined as a multi-level, multifaceted process handling the automatic detection, association, correlation, estimation, and combination of data and information from several sources [9]. Klein [7], generalizes that definition, stating that data could be provided either by a single source or by multiple sources. Both definitions were general and could be applied in different fields, including remote sensing.

Fused data from multiple sensors had several advantages over data from a single sensor:

- If several identical sensors are used then combining data or observations would result in improved estimates, for example of target position or velocity. A statistical advantage can be gained by adding independent data. This result might also be obtained from multiple observations of an individual sensor.

- Relative placement or motion of multiple sensors can improve the observation process.

- Using multiple sensors could help improve observability, by broadening the baseline of physical observables, which can result in improvements.

\section{PROBLEMS}

There were a number of issues associated with data fusion. Many arose from the types of data being fused, the variety of sensor technologies, sensor imperfections and the environment in which the sensors operated. Some challenges were:

\section{A. Data imperfection}

Some data can contain uncertainty and impreciseness. Data fusion algorithms can effectively identify and utilize data redundancy to reduce their effects.

\section{B. Data modality}

Network systems could obtain both homogenous (qualitative) and heterogeneous (physical attributes: audio, visual and tactile measurements of an occurrence). Both can be addressed using data fusion.

\section{Conflicting data}

Fusion of data was sometimes difficult, for example when evidence was required for reasoning using Dempster's rule of combination. To avoid counter-intuitive results, the data fusion algorithm(s) need to be treated with caution [10]. 


\section{Data alignment}

Data from sensors must be transformed into a familiar framework before sensor fusion can occur. A problem associated with data alignment was calibration error and that could be critical to successful use of data fusion [6].

\section{E. Processing framework:}

Data fusion could be centralized or decentralized. Processed sensor data could be applied to machine learning and then represented in a graphical user interface or within a sensor network for real time data comparison. This could be more efficient when compared to the communication load required by a centralized system, for example if measured data was sent to a central processing node for data fusion [6].

\section{SimPle EXAMPLES Of SENSOR FUSION}

A single sensor might not be enough to create a useful intelligent monitoring system. It may misrepresent the process and might contain errors. Multi-sensor based monitoring involved more than one sensor. Multi-sensor fusion is better for improving prediction and obtaining more useful information.

Multi-sensor fusion has proved to be better for the detection of anomalies or faults from defects and has also provided an opportunity for corrective action to be taken to reduce damage to machinery and processes.

This research work used a dataset obtained from the sensors shown in fig. 2. Assumptions were made from state estimation applied to a crude distillation column. The dataset consisted of combined sensor information from $2 \times 2$ and $3 \times 3$ matrices. Before the use of the dataset, it was pre-processed, adjusted and tested with several possibilities to produce different data sets and outcomes. Each shuffled set had the same data set but had different outcomes.

\section{A. Fusion of two sensors}

The complexity of combining two sensors to form a system was characterized by difficulties in representing the uncertainty in observations and in system phenomena that generated observations combining non-correlative information (for example imaging, text and signals) manipulating and maintaining a vast number of alternatives associated with translating large numbers of observations from several entities.

Two sensors are considered in Table I and Table II. Table I is an example of a sensor with two separate types of sensor information (indication and impact) fused as one.

TABLE I. CRUDE VALVE INLET SENSOR INFORMATION

\begin{tabular}{|l|l|l|}
\hline \multirow{2}{*}{ SENSOR } & \multicolumn{2}{|c|}{ Single-Sensor System } \\
\cline { 2 - 3 } & \multicolumn{1}{|c|}{ Indicator } & \multicolumn{1}{c|}{ Impact (Outcome) } \\
\hline $\begin{array}{l}\text { Crude } \\
\text { inlet valve } \\
\text { sensor }\end{array}$ & Crude inlet valve opened & Low risk \\
\cline { 2 - 3 } & Crude inlet valve closed & Low risk \\
\hline
\end{tabular}

More than one sensor needed to be used with sensor fusion to reveal more information than would be achievable from the separate individual sensors.

Table I shows sensor information from a crude inlet valve sensor. There were two possible outcomes (valve opened or valve closed). Indicators showed low risk to the crude distillation column in both cases. When the crude inlet valve was open to allow feed flow to the distillation column, it sent a signal to a sensor indicating fluid flow into the column. When closed, the sensor did not generate any signal indicating flow. In both cases, no threat would be recognized, so impact would always be Low risk.

In Table II, there are two possible indicators, the presence of feed flow detected by the sensor and feed flow not detected by the sensor. These indicators limited the amount of information. Both outcomes indicated an operational condition and so would always show as Low risk without identifying any potential hazard. Relying on the two possible indicators and sets of data in Table II alone would not reveal much useful information.

TABLE II. FEED Flow RATE From Two PossibILITIES

\begin{tabular}{|l|l|l|}
\hline \multirow{2}{*}{ SENSOR } & \multicolumn{2}{|c|}{ Single-Sensor System } \\
\cline { 2 - 3 } & \multicolumn{1}{|c|}{ Indicator } & \multicolumn{1}{c|}{ Impact (Outcome) } \\
\hline \multirow{2}{*}{$\begin{array}{l}\text { Feed flow } \\
\text { rate sensor } \\
\text { from tank }\end{array}$} & Crude inlet valve opened & Low risk \\
\cline { 2 - 3 } & Crude inlet valve closed & Low risk \\
\hline
\end{tabular}

Table III shows the number of possible indicators using a three-way technique to compare sensor information within range, below range and above range. The sensor information outcome was compared to Table II. The first sensor reading within range indicated that there were no threats or possible hazards (Low risk). If the feed flow rate was below the range it still did not indicate a threat.

When the indicator indicated a feed flow rate above range then the sensor would suggest new information, that Impact suggested a moderate risk. That is an improvement on the binary data and could indicate a potentially developing hazard that if not checked could lead to a catastrophic event.

TABLE III. FEED FlOW RATE From THREE POSSIBILITIES.

\begin{tabular}{|l|l|l|}
\hline \multirow{2}{*}{ SENSOR } & \multicolumn{3}{|c|}{ Single Sensor System } \\
\cline { 2 - 3 } & \multicolumn{1}{|c|}{ Indicator } & \multicolumn{1}{|c|}{ Impact (Outcome) } \\
\hline \multirow{3}{*}{$\begin{array}{l}\text { Feed flow } \\
\text { rate sensor } \\
\text { range }\end{array}$} & Feed flow rate welow range & Low risk \\
\cline { 2 - 3 } & Feed flow rate above range & Moderate risk \\
\hline
\end{tabular}

The higher the possible number of indicators the higher the number of possible outcomes and the more useful the information that might be obtained.

Table IV shows a combination of the possible sensor data displayed in Table I and Table II. This represented sensor 
Paper submitted to IEEE 10th International Conference on Intelligent Systems

information using 3-state estimation (within, below and above range) for both the feed flow rate and crude inlet valve. The data combination of both (Table I and II) improved reliability and eliminated mistakes from using improper data types.

Table IV presents a sensor fusion example for a $2 \times 2$ sensor matrix between a feed flow rate sensor and a crude inlet valve sensor. "Feed flow within range" meant the system was operating safely with feed entering the distillation at the required rate. That did not pose any threat. When "feed flow rate was below range', feed entering distillation was slower than expected. That did not pose an immediate threat but could affect quality.

Finally, when the sensor indicated "feed flow rate above range" feed into the distillation column was greater than required and could lead to over-flooding of the distillation column and in turn to pressure build-up. That could result in a process known as "puking'" and that could damage the column and affect product quality.

More and more useful information could be obtained from the data immediately the two sensors were combined. Using the $2 \times 2$ matrix, a colour traffic light system could also be used to indicate operational conditions:

- When both variables were above range this could automatically flag a potential catastrophe (High risk).

- When both variables were below range, it suggests moderate risk.

- If there was a surge in the temperature or pressure (above range) then the combined sensor data indicated that a catastrophic event could be in place (High risk).

- If temperature or pressure fell within range and the combined sensor indicated a sub-optimal operational condition (below range) then the indicator suggested Moderate risk.

Table IV. $2 \times 2$ Sensor Matrix Table (Feed Flow Rate And CRUDE INLET VALVE)

\begin{tabular}{|c|c|c|c|}
\hline \multirow[b]{2}{*}{ SENSOR } & \multicolumn{3}{|c|}{ Two-Sensor System } \\
\hline & Indicator & & $\begin{array}{c}\text { Impact } \\
\text { (Outcome) }\end{array}$ \\
\hline \multirow[b]{2}{*}{$\begin{array}{l}\text { Feed flow rate } \\
\text { sensor }\end{array}$} & $\begin{array}{l}\text { Feed flow rate } \\
\text { within the range }\end{array}$ & $\begin{array}{l}\text { Crude inlet valve } \\
\text { open }\end{array}$ & Low risk \\
\hline & $\begin{array}{l}\text { Feed flow rate } \\
\text { within the range }\end{array}$ & $\begin{array}{l}\text { Crude inlet valve } \\
\text { closed }\end{array}$ & High risk \\
\hline I & $\begin{array}{ll}\begin{array}{l}\text { Feed flow rate } \\
\text { below range }\end{array} \\
\end{array}$ & $\begin{array}{l}\text { Crude inlet valve } \\
\text { closed }\end{array}$ & $\begin{array}{l}\text { Moderate } \\
\text { risk }\end{array}$ \\
\hline \multirow{3}{*}{$\begin{array}{l}\text { Crude inlet } \\
\text { valve sensor }\end{array}$} & $\begin{array}{ll}\begin{array}{l}\text { Feed flow rate } \\
\text { below range }\end{array} \\
\end{array}$ & $\begin{array}{l}\text { Crude inlet valve } \\
\text { open }\end{array}$ & Low risk \\
\hline & $\begin{array}{lll}\begin{array}{l}\text { Feed flow rate } \\
\text { above range }\end{array} & \\
\end{array}$ & $\begin{array}{l}\text { Crude inlet valve } \\
\text { closed }\end{array}$ & High risk \\
\hline & $\begin{array}{l}\text { Feed flow rate } \\
\text { above range }\end{array}$ & $\begin{array}{l}\text { Crude inlet valve } \\
\text { open }\end{array}$ & High risk \\
\hline
\end{tabular}

B. A system from fusing data from three sensors

A three-sensor combination is shown in Tables V to VII. They can be used to describe the patterns formed from combining independent sensors in a systemic way. The results could help to reduce downtime. The example demonstrates how sensor data from a single independent sensor is limited.

Table $\mathrm{V}$ shows the feed flow sensor with three possible readings. Feed flow rate within range involved less risk, compared to the rates below range and above range.

\section{TABLE V. FEED FLOW SENSOR INFORMATION}

\begin{tabular}{|l|l|l|}
\hline \multirow{2}{*}{ SENSOR } & \multicolumn{2}{|c|}{ Three-Sensor System } \\
\cline { 2 - 3 } & \multicolumn{1}{|c|}{ Indicator } & \multicolumn{1}{|c|}{ Impact (Outcome) } \\
\hline \multirow{3}{*}{$\begin{array}{l}\text { Feed flow } \\
\text { rate sensor } \\
\text { range }\end{array}$} & Feed flow rate below range & Low risk \\
\cline { 2 - 3 } & Feed flow rate above range & Moderate risk \\
\hline
\end{tabular}

Table VI shows temperature reading at the reflux. When the temperature at the reflux is within the expected range, it does not pose any threat. But when the temperature falls below the expected margin then there might be a developing hazard and when the temperature at the reflux rises above the critical operational margin (above range) there might be a catastrophe.

TABLE VI. TEMPERATURE SENSOR AT REFLUX

\begin{tabular}{|l|l|l|}
\hline \multirow{2}{*}{ SENSOR } & \multicolumn{1}{|c|}{ Three-Sensor System } \\
\cline { 2 - 3 } & \multicolumn{1}{|c|}{ Indicator } & \multicolumn{1}{|c|}{ Impact (Outcome) } \\
\hline \multirow{4}{*}{$\begin{array}{l}\text { Temperature at } \\
\text { reflux }\end{array}$} & $\begin{array}{l}\text { Temperature at reflux within } \\
\text { range }\end{array}$ & Low risk \\
\cline { 2 - 3 } & $\begin{array}{l}\text { Temperature at reflux below } \\
\text { range }\end{array}$ & Low risk \\
\cline { 2 - 3 } & $\begin{array}{l}\text { Temperature at reflux above } \\
\text { range }\end{array}$ & High risk \\
\hline
\end{tabular}

Sensor information from the pressure reading at the column is shown in Table VII. Pressure at the column within range indicates Low risk, but when pressure falls below the required pressure range or rose above range then there is the potential for a hazard.

TABLE VII. Pressure SENSOR In The Column

\begin{tabular}{|l|l|l|}
\hline \multirow{2}{*}{ SENSOR } & \multicolumn{1}{|c|}{ Three-Sensor System } \\
\cline { 2 - 3 } & \multicolumn{1}{|c|}{ Indicator } & \multicolumn{1}{|c|}{ Impact (Outcome) } \\
\hline \multirow{4}{*}{$\begin{array}{l}\text { Pressure } \\
\text { at column } \\
\text { within the range }\end{array}$} & $\begin{array}{l}\text { The pressure at column below } \\
\text { range }\end{array}$ & Moderate risk \\
\cline { 2 - 3 } & $\begin{array}{l}\text { The pressure at column above } \\
\text { range }\end{array}$ & High risk \\
\hline
\end{tabular}

The output from sensor fusion was a higher level of information and was categorized into the three classes: Low risk, Moderate risk and High risk. Table V to Table VII were combined into a larger matrix to combine data from all three sensors: Feed flow sensor; Temperature sensor at the reflux; and Pressure senor at the column.

Looking at all the possible scenarios from a combined matrix shows patterns in the data that are not available from 
individual sensors. Notable patterns involved sensor readings above range, below sensor range and within sensor range but when the three sensors were combined then more information was revealed.

\section{SENSOR PATterns AND MACHNE LEARNING}

Pattern recognition depended on trend data and information acquired from sensor data. Combining data form multiple sensors requires converting a large amount of data into small pieces of useful information. Pattern recognition algorithms and real-time data were considered for this.

Using clustering methods and pattern recognition, then a system can be completely analysed. The strategy adopted is shown in Fig. 4. The research aims to combine both the potential failure mode of a system with various sensor faults and a scoring technique to analyze and identify systemic risk. The goal was to enhance accuracy and reliability.

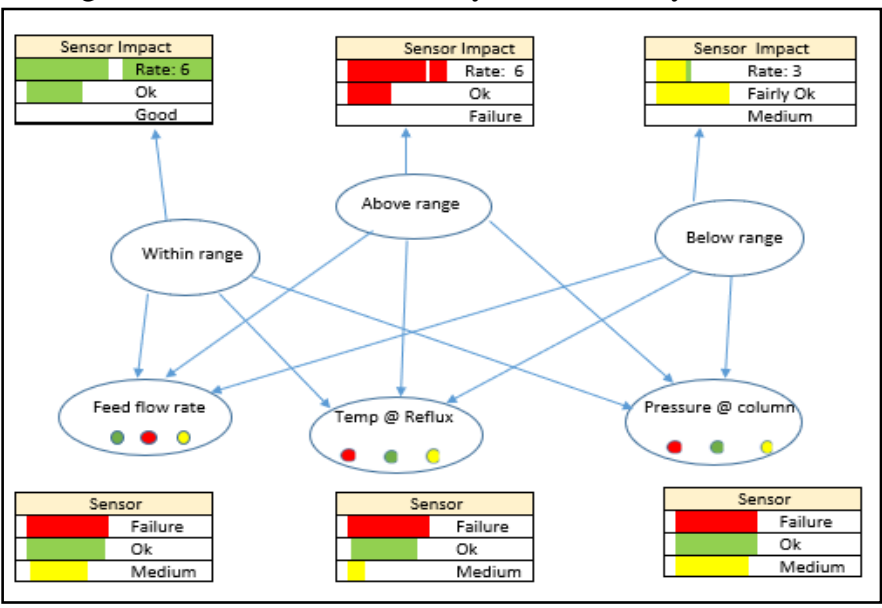

Figure 4. Sensor pattern recognition and failure mode identification

Sensor fusion is used to feed machine learning and to build an intelligent monitoring system. Combining multiple sensors to establish a pattern helps machine learning and allows patterns in data to be recognized (Fig. 5).

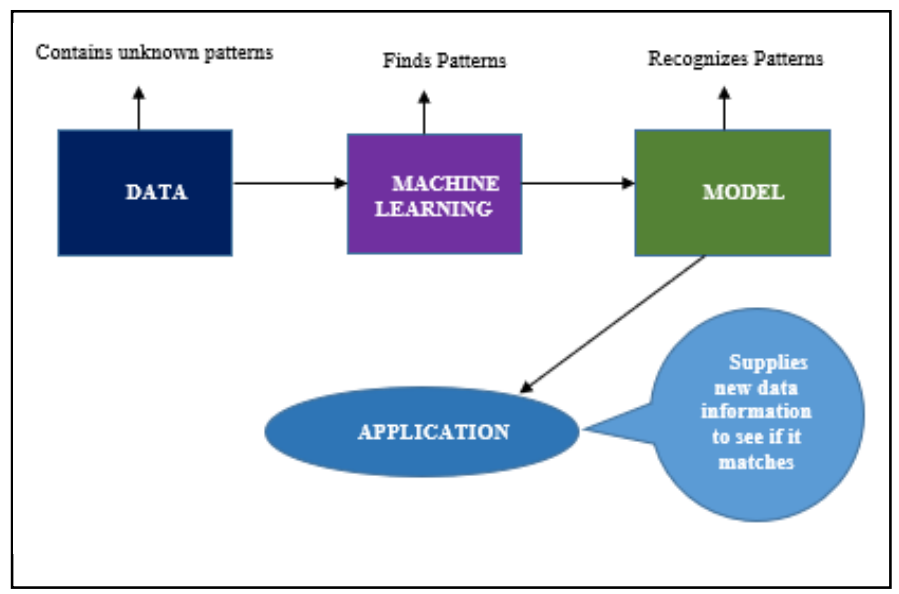

Figure 5. Machine-learning Patterns achieved using sensor fusion

\section{DISCUSSION AND CONCLUSION}

This paper described the use of Artificial Intelligence techniques for sensor fusion. A methodology to obtain intelligent monitoring through multi-sensor fusion for a crude distillation column was presented. The method was demonstrated using some simple examples of input data and output information. Information from simple two and three sensor combinations were considered in the paper.

A state estimation technique was used to transform data from simple $2 \times 2$ into more complicated but more useful $3 \times 3$ matrices. The solution initially used single and combinations of simple binary matrices to predict trends and create a monitoring system.

Fig. 2 shows sensors being considered in the research that are positioned around a crude distillation column. The advantage of using multi-sensor fusion with some of these sensors was presented using some simple examples. The result could improve observability and result in significant improvement. Single individual sensors might not be effective in creating an intelligent monitoring system. Sensor fusion provided more significant information than from separate sensors.

Table I showed sensor data and then information obtained from a crude inlet valve sensor with two possible outcomes (crude inlet valve opened and closed). In Table II, there were two possible indicators, the presence of feed flow detected by the sensor and feed flow not detected. These indicators from Table I and Table II when used alone limited the amount of information that could be obtained (if used separately). The higher the number of indicators then the higher the number of possible outcomes. Relying on the indicators shown separately in Table I and Table II could miss useful information and data for validation.

Table III showed the number of possible indicators using a simple three-way technique as an example and allowed a comparison of sensor information within range, below range and above range. The sensor information outcome when compared to the data in Table I and II provided more sensor and more useful information.

Table IV showed a combination of Table I and Table II, using state estimation (partly suggested by the sort of results shown in Table III). This represented sensor information using a 3-state estimation technique (within, below and above range) of both feed flow rate and from a crude inlet valve. The combination of data from both Table I and Table II improved data reliability, eliminated improper datasets and provided more room for comparison of data information.

The three-sensor combination shown in Tables V-VII helped to establish a pattern from independent sensors to form a systemic way of thinking. This helped improve pattern recognition and that could be used with machine learning to detect anomalies, and predict faults and catastrophe.

A main goal of this work was to verify the potential of machine learning techniques and ways of combining sensor fusion to create pattern recognition to be used in an intelligent monitoring system for a crude oil distillation column. 
Paper submitted to IEEE 10th International Conference on Intelligent Systems

A limitation was a concern with the accuracy and reliability improvements. Future work will investigate phase changes and material balance on sensor fusion performance and the data will be fed into some intelligent control systems that have recently been used to control powered wheelchairs [12-20]. It will also be used with decision making systems [21-23] and decision making algorithms are being investigated [24-27].

\section{REFERENCES}

[1] Bartok J, Habala O, Bednar P, Gazak M, Hluchý L (2010). Data mining and integration for predicting significant meteorological phenomena. Procedia Comput. Sci., 1: 37-46.

[2] Chang CD, Wang CC, Jiang CB (2010). Using Data Mining Techniques for Multi-Diseases Prediction Modeling of Hypertension and Hyperlipidemia by Common Risk Factors. Expert Systems with Applications, In Press, Accepted Manuscript.

[3] Durrant-Whyte, H. (1988). Sensor Models and Multisensor Integration. The International Journal Of Robotics Research, 7(6), 97-113. doi: $10.1177 / 027836498800700608$

[4] Mohaghegh SD (2005). A new methodology for the identification of best practices in the oil and gas industry, using intelligent systems. J. Petrol. Sci. Eng., 49: 239-260.

[5] Hajizadeh E, Davari AH, Shahrabi J (2010). Application of data mining techniques in stock markets: A survey, J. Econ. Int. Finance 2(7): 109118.

[6] Khaleghi, B., Khamis, A., Karray, F. and Razavi, S. (2013). Multisensor data fusion: A review of the state-of-the-art. Information Fusion, 14(1), pp.28-44.

[7] Luo, R., \& Kay, M. (1989). Multisensor integration and fusion in intelligent systems. IEEE Transactions on Systems, Man, And Cybernetics, 19(5), 901-931. doi: 10.1109/21.44007Saybani MR, Teh Ying WAL (2009). Applied Data Mining Approach in Ubiquitous World of Air Transportation. In: Comput. Sci. Convergence Info. Technol., ICCIT '09. Fourth Int. Conf., pp. 1218- 1222.

[8] Klein L.A. (1999). Sensor and Data Fusion Concepts and Applications (second ed.), Society of Photo-optical Instrumentation Engineers (SPIE), Bellingham, WA.

[9] White F.E. (1991). Data Fusion Lexicon, Joint Directors of Laboratories, Technical Panel for C3, Data Fusion Sub-Panel, Naval Ocean Systems Center, San Diego.

[10] Smets, P. (2007). Analyzing the combination of conflicting belief functions Information Fusion, 8 (4) pp. 387-412.

[11] Selim G, Seker S (2011). Signal based approach for data mining in fault detection of induction motor', Sci. Res. Essays 6(22): 47204731.Saybani MR, Teh Ying WAL (2009). Applied Data Mining Approach in Ubiquitous World of Air Transportation. In: Comput. Sci. Convergence Info. Technol., ICCIT '09. $4^{\text {th }}$ Int. Conf., pp. 1218- 1222.

[12] D. A. Sanders, et al. "A Rule-based Expert System to decide on direction and speed of a powered wheelchair," IEEE Proceedings of the SAI Conference on IntelliSys. London, U.K., pp. 426 - 433, 2018.

[13] D. Sanders, G. Tewkesbury, H. Parchizadeh, J. J. Robertson, P. O. Omoarebun, and M. Malik, "Learning to drive with and without intelligent computer systems and sensors to assist," Advances in Intelligent Systems and Computing, vol. 868, Springer, pp. 1171-1181, 2019.

[14] D. A. Sanders, "Non-model-based control of a wheeled vehicle pulling two trailers to provide early powered mobility and driving experiences," IEEE Transactions on Neural Systems and Rehabilitation Engineering, vol. 26 , no. $1,96-104,2018$.

[15] D. Sanders, A. Gegov, G. Tewkesbury, and R. Khusainov, "Sharing driving between a vehicle driver and a sensor system using trust-factors to set control gains," Advances in Intelligent Systems and Computing, vol. 868, Springer, pp. 1182-1195, 2019.

[16] D. Sanders, M. Langner, N. Bausch, Y. Huang, S. A. Khaustov, and S. Simandjuntak, "Improving human-machine interaction for a powered wheelchair driver by using variable-switches and sensors that reduce wheelchair-veer," Intelligent Systems and Applications . Advances in Intelligent Systems and Computing, vol. 1038, pp. 1173-1191, 2019.

[17] D. A. Sanders, A. Gegov, and D. Ndzi, "Knowledge-based expert system using a set of rules to assist a tele-operated mobile robot," in Studies in Computational Intelligence, 751, Springer, 2018, pp. 371-392.

[18] D. A. Sanders et al. "Rule-based system to assist a tele-operator with driving a mobile robot," Lecture Notes in Networks and Systems, 16, Springer, pp. 599-615, 2018.

[19] D. Sanders, A. Gegov, M. Haddad, F. Ikwan, D. Wiltshire, and Y. C. Tan, "A rule-based expert system to decide on direction and speed of a powered wheelchair, Advances in Intelligent Systems and Computing, vol. 868, Springer, pp. 822-838, 2019.

[20] D. Sanders, O. M. Okonor, M. Langner, S. M. Hassan, S. A. Khaustov, and P. O. Omoarebun, "Using a simple expert system to assist a powered wheelchair user," Intelligent Systems and Applications. Advances in Intelligent Systems and Computing, vol. 1037, pp. 662-379, 2019

[21] M. Haddad, D. Sanders, N. Bausch, G. Tewkesbury, A. Gegov, and M. Hassan Sayed, "Learning to make intelligent decisions using an Expert System for the intelligent selection of either PROMETHEE II or the Analytical Hierarchy Process," Advances in Intelligent Systems and Computing, vol. 868, Springer, pp. 1303-1316, 2019.

[22] M. Haddad, D. Sanders, A. Gegov, A, M. Hassan Sayed, Y. Huang, and M. Al-Mosawi, "Combining multiple criteria decision making with vector manipulation to decide on the direction for a powered wheelchair," Advances in Intelligent Systems and Computing, vol. 1037, Springer, pp. 680-693, 2019.

[23] M. Haddad, and D. Sanders, "Selecting a best compromise direction for a powered wheelchair using PROMETHEE," IEEE Transactions on Neural Systems and Rehabilitation Engineering, vol. 27, no. 2, pp. 228235, 2019.

[24] M. Haddad, D. Sanders, G. Tewkesbury, A. Gegov, M. Hassan Sayed, and F. Ikwan, "Initial results from using Preference Ranking Organization METHods for Enrichment of Evaluations to help steer a powered wheelchair," Advances in Intelligent Systems and Computing, vol. 1037, Springer, pp. 648-661, 2019.

[25] M. Haddad, D. Sanders, and N. Bausch, "Selecting a robust decision making method to evaluate employee performance," International Journal of Management and Decision Making, vol. 18, no. 4, pp. 333$351,2019$.

[26] M. Haddad, D. Sanders, and G. Tewkesbury, "Selecting a discrete Multiple Criteria Decision Making method to decide on a corporate relocation," Archives of Business Research, vol. 7, no. 5, pp. 48-67, 2019.

[27] D. Sanders, D. C. Robinson, M. Hassan Sayed, M. Haddad, A. Gegov, and N. Ahmed, "Making decisions about saving energy in compressed air systems using Ambient Intelligence and Artificial Intelligence," Advances in Intelligent Systems and Computing, vol. 869, Springer, pp. 1229-1236, 2018. 